\title{
Predictors of Multiple Micronutrient Powder Intake Adherence among Children Aged 6-23 Months in Rasuwa District, Nepal: A Cross-sectional Study
}

\begin{abstract}
Ashish Timalsina ${ }^{1,2}$, Rajan Paudel', Dipak P Upadhyaya ${ }^{1,3}$, Sujay Bhattacharya ${ }^{4}$, Bihari S Kuikel ${ }^{5}$, Naresh P Joshi ${ }^{6}$, Sunil Adhikari', Aye A Aung ${ }^{7}$

${ }^{1}$ Central Department of Public Health, Institute of Medicine, Tribhuvan University, Kathmandu, Nepal, ${ }^{2}$ Ministry of Health and Population, Kathmandu, Nepal, ${ }^{3}$ School of Medicine, Case Western Reserve University, Euclid Ave, Cleveland USA, ${ }^{4}$ Action Against Hunger | Action Contre la Faim (ACF), Kathmandu, Nepal, ${ }^{5}$ Department of Public Health, School of Medical Sciences, Kathmandu University, Dhulikhel, Nepal, ${ }^{6}$ Partnership for Social Development (PSD), Kathmandu, Nepal, ${ }^{7}$ Department of Medical Services, Ministry of Health and Sports, Myanmar
\end{abstract}

\section{Corresponding author:}

\section{Rajan Paudel, BPH, MPH}

Central Department of Public Health, Institute of Medicine, Tribhuvan University, Kathmandu, Nepal

Email:paudel.rajan@gmail.com

Submitted : Jun 5, 2020

Accepted : July 28, 2020

\begin{abstract}
Introduction

Breastfeeding would not be sufficient to meet the micronutrient requirement of children after six months and more prone to iron deficiency anemia. Micronutrient powder (MNP) can be mixed with semi-solid food to feed the children aged 6-23 months, contains 12 different micronutrients, one of the appropriate strategies. The study's objective was to assess adherence to MNP and its predictors among children aged 6-23 months in Rasuwa district of Nepal.
\end{abstract}

\section{Methods}

A cross-sectional study was conducted in the Uttargaya rural and the Kalika rural municipality of Rasuwa district among 200 mothers of children aged 6-23 months who were fed MNP. Proportionate random sampling was used to select eligible mothers for interviews, and a semi-structured questionnaire was employed for data collection. Multivariate logistic regression was used to obtain adjusted odds ratio with $95 \%$ C.I.

\section{Results}

Sample mean was calculated among 155 mothers who received 60 sachets of MNPs; $41.3 \%$ had adhered to 60 sachets intake of MNP. The mean age of the mother was $25.29 \pm 5.3$ years and the mean age of children was 14. $66 \pm 5.2$ months. In bivariate analysis, the mother having one child less than five years (COR=0.5, $95 \% \mathrm{Cl}: 0.24-1.0)$ and $\mathrm{MNP}$ received from the health facility (COR=1.96, 95\% Cl: $1.02-3.76)$ were statically significant. Further, multivariate analysis, a mother who accepted the properties of MNP (AOR=2.52, 95\% Cl: 1.27-5.00), was associated with high adherence.

\section{Conclusion}

Acceptability of MNP by the mother is the key to increase adherence to MNP. The distribution of MNP from a health facility, tailored with nutrition education is essential to improve adherence to MNP.

Keywords: Adherence, children, multiple micronutrient powder, Nepal 


\section{INTRODUCTION}

A $n$ estimated $40-50 \%$ of under-five children in low-income countries are suffering from iron deficiency. ${ }^{1}$ World Health Organization recommends home fortification of foods with micronutrient powder to improve the iron status of the body and reduce iron deficiency anemia among children aged 6-23 months. ${ }^{2}$ Micronutrient deficiency is due to insufficient food intake and consumption of food deficit with vitamins, iron, and zinc. The impact of micronutrient deficiency is less visible, and conditions are recognizable only in severe deficiency. ${ }^{3}$ After six months of age, breast milk is not enough to meet the nutritional requirement, and this is the most vulnerable time for young children to become undernourished. ${ }^{4}$ Since iron intake is not sufficient after six months of age, food should be reinforced to prevent delay in growth, and for this treatment-based food with iron supplementation found to be cost-effective. Supplementation of micronutrient powder for home fortification is considered a public health intervention to address the mortality and morbidity due to micronutrient deficiency among children. It has been proven to be safe, effective, and successful in reducing the prevalence of iron deficiency anemia. 5,6

The Government of Nepal (GON) introduced Micro Nutrient Powder (MNP) locally branded as "MNP" each sachet of MNP contains 12 micronutrients including iron, zinc, and other micronutrients. ${ }^{7}$ Supplementation program as a preventive measure to address anemia in 2007 from the National Nutrition Priority Workshop and home fortification of complementary food with the MNP program was integrated with Infant, and Young Child Feeding since 2009 for 6-23 months of children, with UNICEF support. In 2009 Ministry of Health and Population conducted a pilot study in Parsa and Rupandehi. The feasibility study's outcome was to develop the local name of MNP as "Baal Vita," agreed for supplementation to children age 6-23 months and MNP packaged with IYCF counseling message. Effective counseling on nutrition, nutrition education, and follow up to the caregiver is essential to improve coverage and comply with the recommended dose of MNP.8

Nevertheless, in the FY 2074/75, less than 50 percent of children aged 6 to 23 months had taken their first dose of multiple micronutrient powder; however, the 3rd cycle of intake is drastically low at 15.6 percent. $^{9}$ Similarly, in Rasuwa, despite the year-round availability of MNP in health facilities, all children (100\%) had completed the first cycle; only $46 \%$ of children had completed the third cycle. ${ }^{10}$ Despite this long and continuous effort from the government and non-government sectors, the consumption of the $3^{\text {rd }}$ cycle of MNP intake was shallow in Rasuwa district. ${ }^{10}$ So this study gives predictors related to the low adherence of MNP; we have seen a considerable gap between adherence to the third dose of MNP in Rasuwa district since more than $90 \%$ of children do not consume MNP.11 Given this backdrop, we aimed to identify the adherence to MNP and its contextual predictors of adherence to MNP among children aged 6-23 months in Rasuwa district, Nepal, to improve MNP intake adherence and program impact ultimately.

\section{METHODS}

We conducted a cross-sectional study in two rural municipalities of Rasuwa district Nepal, namely Kalika and Uttargaya rural municipality, among the children aged 6-23 months with MNP supplied by government health facility in the past 60 days. For this study, adherence to MNP refers to the extent to which children aged 6-23 months fed with one sachet MNP per day for 60 days. Children who consumed 60 sachets as high adherence and those $<60$ sachets as low adherence. In this study, knowledge of a mother about anemia means an understanding of the mother about anemia. It was measured through five questions on causes, signs, consequences, and prevention/treatment. Similarly, mother's knowledge about MNP was measured through ninee questions on product information, dosage, and usage. It was categorized as adequate and inadequate knowledge based on PCA scoring.

For the availability of MNP, we considered the place from where the mother received MNP packets. Acceptability scores were calculated for two dimensions; first, the ease of use and second organoleptic properties. The mean ease of use was calculated based on three items, i.e., packaging of MNP, properties of MNP, and storage of MNP using a 3-point Likert scale ("Agree", "Neutral" and "Disagree"). The organoleptic properties were calculated based on four items i.e., color, taste, odor, and overall, the likeability of food after mixing with MNP.

We randomly selected two municipalities. A list of all children who were fed MNP was obtained from Female Community Health Volunteer (FCHV) through Vitamin A register. The sample size was calculated with finite population size. The total number of children aged 6-23 months in the Rasuwa district was 1406. The sample size calculated was 181 , and with a $10 \%$ non-response rate, the size became 199. We had approached 200 mothers for the consent and all the mothers gave their written informed consent. Therefore, we collected information from 200 mothers, which was the final sample size. From each Kalika and Uttargaya rural municipality, the required sample size was calculated using proportionate to population size (PPS).

Data collection was carried out in February- 
Table 1. Socio-demographic characteristics of Mothers of children aged 6-23 months $(n=155)$

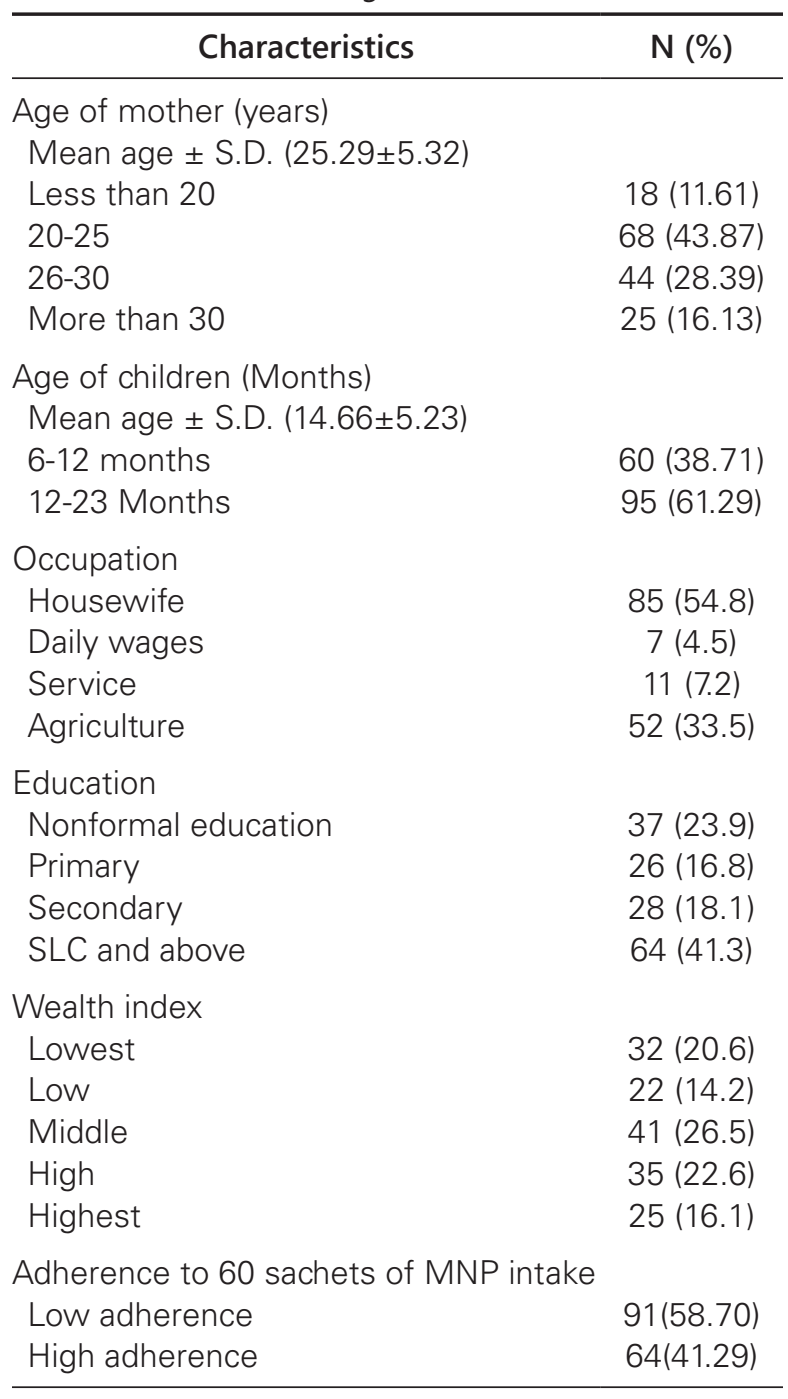

March 2020 using a semi-structured interview questionnaire. STATA version 13 was used for data analysis. Bivariate analysis and multivariate analysis were done to test the significant differences examine the effects of independent predictors. Adjusted Odds Ratio (AOR) was calculated with a $95 \%$ confidence interval. The ethical review committee approved the study at the Institute of Medicine (approval no: 263(6-11)-E2 076/077) and Nepal Health Research Council (approval no: 21/2020 MT). Participants provided verbal and written consent to participate in the study, and it was voluntary and anonymous.

\section{RESULTS}

More than half of the children (61.29\%) were 12-23 months old, with a mean age of $14.66 \pm 5.3$ months. The mother's age ranged from 16 to 40 years, with a mean age score $(25.29 \pm 5.3)$. The total number of live children ranged from one child to five children. About half of the mother $(50.03 \%)$ had one child. More than 4 in 10 mothers (41.3\%) had education level SLC and above, and most mothers were housewives $(54.8 \%)$ by occupation. More than one in four (26\%) families were middle quintiles followed by high $(22.6 \%)$ and lowest $(20.6 \%)$. The sample mean of high adherence to intake of 60 sachets of MNP was $41.3 \%$, as depicted on the last horizontal line of Table 1.

Out of total mothers, about half of the mothers had adequate knowledge of anemia (50.49\%) and knowledge of MNP (48.39\%). About two in three mothers $(66.45 \%)$ did not accept the organoleptic properties. For 4 in 5 mothers $(82.58 \%)$, there was regular availability of MNP, but 1 in 5 mothers there was no regular availability of MNP (Table 2).

Table 2. Mother's knowledge of Anaemia and MNP and its acceptability and availability

\begin{tabular}{|c|c|c|c|}
\hline \multirow{2}{*}{ Characteristics } & Non adherence $(n=91)$ & Adherence (64) & Total $(n=155)$ \\
\hline & n (\%) & n (\%) & n (\%) \\
\hline \multicolumn{4}{|l|}{ Knowledge on MNP } \\
\hline Non-Adequate & $48(52.75)$ & 27 (42.19) & $80(51.61)$ \\
\hline Adequate & $43(47.25)$ & $37(57.81)$ & 75 (48.39) \\
\hline \multicolumn{4}{|l|}{ Knowledge on Anemia } \\
\hline Non-Adequate & $26(43.33)$ & $25(58.14)$ & $51(49.51)$ \\
\hline Adequate & $34(56.67)$ & $18(41.86)$ & $52(50.49)$ \\
\hline \multicolumn{4}{|l|}{ Organolaptic Properties } \\
\hline Non-accepted & $38(41.76)$ & $14(21.88)$ & $52(33.55)$ \\
\hline Accepted & $53(58.24)$ & $50(78.13)$ & $103(66.45)$ \\
\hline \multicolumn{4}{|l|}{ Availability of MNP } \\
\hline Non- regular & 18 (19.78) & $9(14.06)$ & $27(17.42)$ \\
\hline Regular & $73(80.22)$ & 55 (85.94) & $128(82.58)$ \\
\hline \multicolumn{4}{|l|}{ MNP Vita Received from } \\
\hline $\mathrm{FCHV}$ & $57(62.64)$ & $30(46.88)$ & $87(56.13)$ \\
\hline $\mathrm{HF}$ & $34(37.36)$ & $34(53.13)$ & $68(43.87)$ \\
\hline
\end{tabular}


Table 3. Socio-demographic factors associated with adherence to MNP from binary logistic regression

\begin{tabular}{|c|c|c|c|}
\hline Characteristics & Crude odds ratio (COR) & $95 \% \mathrm{Cl}$ & $p$-value \\
\hline \multicolumn{4}{|l|}{ Age of mother } \\
\hline Less than 20 years & Ref & & \\
\hline $20-25$ years & 2.11 & $0.73-6.11$ & 0.17 \\
\hline $26-30$ years & 1.72 & $0.56-5.2$ & 0.34 \\
\hline More than 30 years & 3.34 & $0.94-11.85$ & 0.06 \\
\hline \multicolumn{4}{|l|}{ Age of child } \\
\hline 6-12 months & Ref & & \\
\hline 13-23 months & 1.43 & $0.74-275$ & 0.27 \\
\hline \multicolumn{4}{|l|}{ No. of children under 5 years } \\
\hline No child of 23-59 months & Ref & & \\
\hline One child of $<5$ years & 0.5 & $0.25-1.00$ & 0.05 \\
\hline Two children of $<5$ years & 1.1 & $0.24-4.71$ & 0.93 \\
\hline \multicolumn{4}{|l|}{ Education } \\
\hline SLC or more & Ref & & \\
\hline Less than secondary & 0.76 & $0.40-1.45$ & 0.41 \\
\hline \multicolumn{4}{|l|}{ Wealth index } \\
\hline Lowest & Ref & & \\
\hline Low & 0.50 & $0.16-1.51$ & 0.22 \\
\hline Middle & 0.63 & $0.24-1.61$ & 0.33 \\
\hline High & 0.71 & $0.26-1.89$ & 0.496 \\
\hline Highest & 1.07 & $0.36-3.15$ & 0.91 \\
\hline
\end{tabular}

Table 4. Knowledge, availability and acceptability factors associated with adherence to MNP from binary logistic regression

\begin{tabular}{|c|c|c|c|}
\hline Characteristics & Crude odds ratio (COR) & $95 \% \mathrm{Cl}$ & $\mathrm{p}$-value \\
\hline $\begin{array}{l}\text { Knowledge factor } \\
\text { Knowledge on anemia } \\
\text { Non-Adequate } \\
\text { Adequate }\end{array}$ & $\begin{array}{c}\text { Ref } \\
0.81\end{array}$ & $0.37-1.78$ & 0.16 \\
\hline $\begin{array}{l}\text { Knowledge on Baal Vita } \\
\text { Non-Adequate } \\
\text { Adequate }\end{array}$ & $\begin{array}{c}\text { Ref } \\
0.96\end{array}$ & $0.50-1.81$ & 0.9 \\
\hline $\begin{array}{l}\text { Availability factor } \\
\text { Baal Vita received from } \\
\text { FCHV } \\
\text { HF }\end{array}$ & $\begin{array}{l}\text { Ref } \\
1.96\end{array}$ & $1.02-3.76$ & $0.04^{*}$ \\
\hline $\begin{array}{l}\text { Availability of MNP } \\
\text { Non- regular } \\
\text { Regular }\end{array}$ & $\begin{array}{l}\text { Ref } \\
1.42\end{array}$ & $0.62-3.28$ & 0.4 \\
\hline $\begin{array}{l}\text { Acceptability of MNP } \\
\text { Non-accepted } \\
\text { Accepted }\end{array}$ & $\begin{array}{l}\text { Ref } \\
2.52\end{array}$ & $1.27-5.00$ & $0.01^{*}$ \\
\hline
\end{tabular}


Table 5. Predictors of MNP intake adherence form multiple logistic regression

\begin{tabular}{|c|c|c|c|c|c|c|}
\hline Characteristics & $\begin{array}{l}\text { Crude odds } \\
\text { ratio (COR) }\end{array}$ & $95 \% \mathrm{Cl}$ & $\mathrm{p}$-value & AOR & $95 \% \mathrm{Cl}$ & $\mathrm{p}$-value \\
\hline \multicolumn{7}{|l|}{ No of children under 5 years } \\
\hline One child of $<5$ years & 0.5 & $0.25-1.00$ & 0.05 & 0.76 & $1.10-4.48$ & 0.35 \\
\hline Two children of $<5$ years & 1.1 & $0.24-4.71$ & 0.93 & & & \\
\hline $\begin{array}{l}\text { MNP Received from } \\
\text { FCHV } \\
\text { HF }\end{array}$ & $\begin{array}{l}\text { Ref } \\
196\end{array}$ & $102-376$ & $0.04^{*}$ & 169 & $0.83-324$ & 0.14 \\
\hline \multicolumn{7}{|l|}{ Acceptability of MNP } \\
\hline Non-accepted & Ref & & & & & \\
\hline Accepted & 2.52 & $1.27-5.00$ & $0.01^{*}$ & 2.22 & $0.13-1.33$ & $0.02^{*}$ \\
\hline
\end{tabular}

A higher adherence with MNP was observed among mothers having one child less than five years of age as compared to mothers who did not have any child of 23-59 months of age, though the statistical significance was borderline (COR=0.5, 95\% Cl: 0.25-1.00). Other sociodemographic factors, such as the age of mother, age of a child, education of mother, and wealth index, were found not statistically significant in the analysis (Table 3).

The odds of having adherence to MNP were 1.96 times higher in mothers who received MNP form health facility $(\mathrm{COR}=1.96,95 \% \mathrm{Cl}: 1.02-3.76)$ than the counterparts who received MNP from FCHV. Mothers who accepted the properties of MNP (95\% Cl: 1.27-5.00) seemed to have odds of 2.52 times than the mother who did not.

Only statistically significant independent variables in bivariate analysis were included in the final multivariate analysis. Multiple logistic regression analysis was carried out to obtain adjusted odds ratios. In the final model, only the acceptance of properties of MNP by children was 2.52 times higher odds of adherence to MNP (95\% Cl: 1.275.00). In addition, MNP received from HF had 1.69 times the odds of adherence with MNP with 95\% $\mathrm{Cl}$ that bordered the significance of 0.83-3.24.

\section{DISCUSSION}

Home fortification of food with MNP is one of the major strategies to address micronutrient deficiency in children. Therefore, in Nepal since 2009, the distribution of MNP sachets has been started to address the Iron Deficiency Anemia (IDA). Since sachets are easier to use and have better acceptance, it improves adherence to MNP. This is a cross-sectional study to measure the adherence of MNP at the community level. There found that at least one child of less than five years, MNP received form HF and acceptance of MNP are positively associated with adherence to MNP. The study found adherence of $41.3 \%$ among children age 6-23 months. The study carried out in Bangladesh showed adherence of $70 \% .{ }^{12}$ For a similar study, two months schedule of daily feeding MNP supplementation, the adherence was $81-100 \% .13,14$ Most of the studies were controlled where health workers regularly monitored the intervention. This might be the reason for higher adherence in these studies.

The age of the mother and age of the child was not significantly associated with adherence to MNP. One study conducted in Bangladesh showed no relation between the mother and child's age to the adherence to MNP.12 A pilot study conducted in Nepal is consistent with our study. ${ }^{15}$ Like this study, the education level of the mother did not make any difference in adherence to MNP. ${ }^{12}$ Nevertheless, the research conducted in Peru showed that there was a significant difference in the education level of mother and adherence to MNP. ${ }^{16}$ A study conducted in Nepal resulted in the mothers who had no education level $(p=<0.001)$ were associated with high adherence to MNP. ${ }^{17}$ In the majority of the study, adherence was associated with the mothers who had no education. In our study, there were no illiterate mothers, so that it may be the reason for such a result. For this study, illiterate means those mothers who can neither read nor write at all. No illiterate mother in the study area could result from many nonformal education programs conducted in the area.

The wealth index is a relative estimation of the economic status of households in our study. Though, the family with middle economic status had high coverage of MNP, there was no significant association between wealth index and adherence. In contrast, the study conducted in Nepal showed that the household with the low economic condition had high adherence to MNP. ${ }^{18}$ This might be because people with low economic status did not know the importance of food supplementation, 
and people with high economic status did not need the supplementation.

Regarding the knowledge of anemia and MNP, there was no significant association with adherence. Likewise, a cross-sectional study conducted in Bangladesh, knowledge score did not affect the adherence to MNP.12 But a cross-sectional pilot study conducted in Kapilbastu and Achham, including 2578 children aged 6-23 months, knowledge on the appropriate use of MNP is associated with adherence to MNP. ${ }^{19}$ Health workers had a significant influence in adherence to MNP since mothers who received MNP from health facility had higher adherence than mothers received MNP from FCHV. Most mothers received MNP form FHCV $(56.13 \%)$, and only about $43.87 \%$ received from HF. In contrast to our study, a pilot study conducted in Rupandehi and Parsa, there was high adherence among mothers who received MNP form FCHV $(p=$ $<0.001) .17$ In rural areas, the distribution of MNP by FCHV had higher coverage.

Acceptability of the MNP was determined through the ease of use of MNP and organoleptic properties of MNP. The mean ease of use summary score was $3.2 \pm 0.81$. It was calculated based on three items i.e., packaging of MNP, properties of MNP, and storage of MNP using a 3-point Likert scale. Almost 9 out of 10 mothers disliked the ease of use for MNP (Data not presented in the table). This study resulted that the mother who found it easy to use and accept the organoleptic properties of MNP were more likely to have adherence than the mothers who did not. A study of Nepal revealed that the child who did not like the food after mixing with MNP had low odds of adherence than as compared to the child who wanted the properties of food after mixing with the MNP. ${ }^{18}$ Similarly, compared to the mothers who did not recognize any organoleptic changes in food after mixing with MNP were more likely to adhere than the mother who noticed. ${ }^{19}$ In this study, we also felt that mothers had some difficulties in understanding and responding to the questions related to the acceptance of MNP. The reason for this result could be due to this, there was an association between acceptance of properties of MNP and adherence to MNP.

While interpreting our study's findings, some limitations should be considered in generalizing the results, which are applicable for a similar settings and context instead of throughout the country. Most of the study measured adherence in a controlled setting where they count the number of used and unused packets regularly. ${ }^{14,20,21}$ In our study, used sachets were not available, and only the unused sachets were counted only in the case where the child was currently feeding. Therefore, we have to rely on the mother's ability to recall the information to calculate the adherence.

\section{CONCLUSION}

Acceptability of MNP by the mother is the key to increase adherence to MNP. In the view to address low adherence issues, the distribution of MNP from a health facility, tailored with nutrition education, counseling, and follow up to the mothers are essential to improve adherence to MNP. Program managers should be concerned about predictors and design comprehensive approaches that increase adherence to MNP at the community level. FCHVs will be the appropriate agent to follow up to ensure the sustained use of MNP. Additionally, intermittent formative studies should be warranted to minimize information biases and to improve MNP intake adherence and program impact ultimately.

\section{CONFLICT OF INTEREST}

None declared.

\section{FUNDING}

The study was partially funded by Nepal Health Research Council to implement the study (Grant Number: 1585-2020).

\section{ACKNOWLEDGEMENTS}

We are thankful to our study participants, NHRC and TU, Central Department of Public Health.

\section{REFERENCES}

1. UNICEF - Nutrition [Internet]. [cited 2020 Aug 23]. Available from: https://www.unicef.org/nutrition/23964_iron.html

2. World Health Organization. Guideline: use of multiple micronutrient powders for point-of-use fortification of foods consumed by infants and young children aged 6-23 months and children aged 2-12 years [Internet]. [cited 2020 Aug 23]. Available from: https://www. who.int/publications-detail-redirect/9789241549943

3. Bhandari S, Banjara MR. Micronutrients Deficiency, a Hidden Hunger in Nepal: Prevalence, Causes, Consequences, and Solutions [Internet]. International Scholarly Research Notices. 2015 [cited 2019 Feb 11]. Available from: https://www.hindawi.com/journals/ isrn/2015/276469/

4. UNICEF Nepal. NNMSS Report 2016.pdf [Internet]. [cited 2019 Feb 11]. Available from: https://www.unicef.org/nepal/sites/unicef.org. nepal/files/2018-08/NNMSS\%20Report\%202016.pdf

5. Tropical Disease Research Centre, UNICEF and Ministry of Health, Zambia. MNP Pilot Study for Development of a Micronutrient Powder Home Fortification Program to Combat Anaemia Among Children 6-23 Months in Zambia - ICH GCP - Clinical Trials Registry [Internet]. [cited 2019 Feb 11]. Available from: https:/lichgcp.net/ clinical-trials-registry/NCT01878734

6. Munares-García 0, Gómez-Guizado G, Munares-García 0, Gómez-Guizado G. Adherence to multiple micronutrient powders and associated factors in children aged 6 to 35 months treated in sentinel health facilities, Ministry of Health of Peru. Rev Bras Epidemiol. 2016;19:539-53.

7. Serdula MK, Lundeen E, Nichols EK, Imanalieva C, Minbaev M, Mamyrbaeva T, et al. Effects of a large-scale micronutrient powder and young child feeding education program on the micronutrient status of children 6-24 months of age in the Kyrgyz Republic. Eur 
J Clin Nutr. 2013;67:703.

8. Department of Health Services, Nepal. Annual_Report_2073-74. pdf [Internet]. [cited 2019 Feb 11]. Available from: https://dohs. gov.np/wp-content/uploads/2018/04/Annual_Report_2073-74. pdf

9. Action Against Hunger, Nepal. A narrative report of household multiple micronutrient powder and, infant and young child feeding coverage and access survey, Rasuwa. Action Against Hunger, Nepal; 2017.

10. Department of Health Services, Nepal. Annual_ Report_2074-75-2017-2018.pdf [Internet]. Google Docs. [cited 2019 Nov 2]. Available from: https://drive.google.com/ file/d/1CsPIrYFKjgluZxWEEM5oI0R60mzdDcA7/view?usp=drive_ open\&usp=embed_facebook

11. Ministry of Health and Population, Nepal; New ERA; UNICEF; EU; USAID; and CDC. 2018. Nepal National Micronutrient Status Survey, 2016. Kathmandu, Nepal: Ministry of Health and Population, Nepal. [Internet]. [cited 2019 Feb 25]. Available from: https://www.unicef.org/nepal/media/1206/file

12. Angdembe MR, Choudhury N, Haque MR, Ahmed T. Adherence to multiple micronutrient powder among young children in rural Bangladesh: a cross-sectional study. BMC Public Health. 2015;15:440.

13. de Barros SF, Cardoso MA. Adherence to and acceptability of home fortification with vitamins and minerals in children aged 6 to 23 months: a systematic review. BMC Public Health. 2016 Dec 1;16(1):299.

14. Lemaire $M$, Islam $Q S$, Shen $H$, Khan MA, Parveen $M$, Abedin $F$, et al. Iron-containing micronutrient powder provided to children with moderate-to-severe malnutrition increases hemoglobin concentrations but not the risk of infectious morbidity: a randomized, double-blind, placebo-controlled, noninferiority safety trial. Am J Clin Nutr. 2011;94:585-93.

15. Mirkovic KR, Perrine CG, Subedi GR, Mebrahtu S, Dahal P, Staatz $C$, et al. Predictors of micronutrient powder intake adherence in a pilot programme in Nepal. Public Health Nutr. 2016;19:1768-76.

16. Munares-García 0, Gómez-Guizado G. Adherencia a multimicronutrientes y factores asociados en niños de 6 a 35 meses de sitios centinela, Ministerio de Salud, Perú. Rev Bras Epidemiol. 2016;19:539-53.

17. Jefferds MED, Mirkovic KR, Subedi GR, Mebrahtu S, Dahal P, Perrine CG. Predictors of micronutrient powder sachet coverage in Nepal. Matern Child Nutr. 2016;11:77-89.

18. Mirkovic KR, Perrine CG, Subedi GR, Mebrahtu S, Dahal P, Jefferds MED. Micronutrient powder use and infant and young child feeding practices in an integrated program. Asia Pac J Clin Nutr. 2016;25:350-5

19. Locks LM, Dahal P, Pokharel R, Joshi N, Paudyal N, Whitehead RD, et al. Infant and Young Child Feeding (IYCF) Practices Improved in 2 Districts in Nepal during the Scale-Up of an Integrated IYCF and Micronutrient Powder Program. Curr Dev Nutr [Internet]. 2018 [cited 2019 Feb 25];2. Available from: https://academic.oup.com/ cdn/article/2/6/nzy019/4985834

20. Hyder SM, Haseen F, Rahman M, Tondeur M, Zlotkin S. Effect of Daily versus Once-Weekly Home Fortification with Micronutrient Sprinkles on Hemoglobin and Iron Status among Young Children in Rural Bangladesh. Food Nutr Bull. 2007;28:156-64.

21. Ip H, Hyder SMZ, Haseen F, Rahman M, Zlotkin SH. Improved adherence and anaemia cure rates with flexible administration of micronutrient Sprinkles: a new public health approach to anaemia control. Eur J Clin Nutr. 2009;63:165-72. 